\title{
EEN WELVAARTSPLAN VOOR SURINAME IN 1770
}

voorgesteld door Gouverneur Jan Nepveu

door

\section{Fred. OUdschans Dentz}

Een welvaartsplan voor Suriname is niet nieuw. Reeds in de 18de eeuw stelde gouverneur JAN NePVEU zulk een plan op, nl. in 1770. Hij was een man die de Kolonie grondig kende. In de 45 jaren welke hij in dienst van de Sociëteit was geweest klom hij op van klerk tot gouverneur. Hij leefde in een tijd, toen men grote activiteit ontplooide in de bestrijding der weglopers (marrons). Van het ,,korps vrynegers" (1771) was hij de stichter alsmede van het ,,korps jagers” (1772).

$\mathrm{Zijn}$ plan was het district Saramacca tot grote bloei te brengen door de aanleg van talrijke suikerplantages. Als een goed administrateur maakte hij een nauwkeurige becijfering voor de aanleg van een suikerstaat, welke in het derde jaar van aanleg winst zou kunnen opleveren.

Zijn gedachten gingen uit naar de stad Amsterdam, die wel een 10- tot 12 tal van deze suikerplantages zou kunnen aanleggen, waarvoor genoeg goed land voorhanden was. Voor de bewoners van het vaderland zou zijn project grote welvaart kunnen brengen.

Maar tevens gingen zijn gedachten uit naar de veiligheid van dergelijke plantages. De aanleg van het cordonpad dient dan voortgezet te worden en ,,alles ingeslooten te worden, waardoor ook al de Rest vande colonie zoo verre die nu buyten 't cordon is, in zeekerheid zou gebragt zyn."

Reeds had NEPVEU ter beveiliging van de plantages en van de residentie van de Gouverneur voorgesteld de hoofdplaats van de kolonie te verplaatsen, maar van dit evacuatieplan is niets gekomen (zie Tijdschr. Ned. Aardr. Gen. 64, 1947, p. 235).

Wat het district Saramacca aangaat werd door toedoen van gouverneur-generaal DE FRIDERICI, in het laatst van de 18de eeuw, de aanleg van plantages ter hand genomen. Post Groningen ontving zijn naam van gouverneur-generaal WichERS in 1790, naar zijn geboorteplaats.

Het welvaartsplan van NEPVEU volgt hieronder. Wij vonden dit in de stukken afkomstig van JAN NEPVEU, door dr J. DE Hullu geïnventariseerd (Algemeen Rijksarchief, no. 22, I stuk).

Propositiën ter Etablisseeringe van Plantagien aan de rivier Sarameca behoorende tot de Colonie van Suriname op de vaste kust van Guiane in West-Indien. Ao 1770 is de voorsz. Rivier van Sarameca opgenoomen door den Capt. der Artillery \& Inspecteur van Straaten en den Capt. 
Ingenieur Hurter die van de schoone gelegenheid en heerlyke Landeryen aan dezelve leggende hebben verslag gedaan Ao 1771 overgesonden, dog de mond van dezelve Rivier is ondiep en gevaarlyk voor scheepen en vaartuygen; weshalven geprojecteerd was een doorsnijding of ten minsten een weg te doen maaken van daar na Paramaribo, daardoor men omtrends 5-6 uuren alles aan Paramaribo zou kunnen transporteeren. Dit werk zoude zeer voordeelig voor 't vaderland weezen, vermits aldaar goede zuyker Landen gevonden worden; bekent zynde dat de cultuure van Zuyker in die Colonie zeer is vermindert, door de meerder aanbrenginge van coffy, Catoen etc. weshalven die Landen zouden kunnen uytgegeeven worden, mits op dezelve zuyker Plantagien zoude worden aangelegt, alleenlyk met consent om zooverre de Landeryen daartoe voordeeliger mogten zyn, teffens daarby ook andere Producten te moogen cultiveeren.

De geme Colonie die reets voorheen 28 a 30 Duysend oxhoofden zuyker heeft geleeverd, geeft thans 17 a 20 duysend oxhoofden 't welk op verre na, en moogelyk wel het tiende gedeelte niet uytmaakt van de zuyker die in de Vereenigde Provincien geconsumeerd word, soveel uit de Oost Indien aangebragt er onder begreepen. Weshalve men continuulyk van de andere Natien (die sig voorsigtiglyk meerder, en wel doorgaants in de West Indien principalyk op dat Product hebben toegelegt) 't mancqueerende moet trekken en betaalen soodat de voordeelen die men van de Etablisseeringe van eenige zuyker Plantagien, wyl men daartoe nog bekwaam Land voorhanden heeft, considerabel zoude zyn voor de Balance van Commertie, voor de Navigatie, voor de meerdere Vertiering en Emplooy van Menschen in den Vaderlande en teffens voor die geene die in zoodanige onderneeminge zouden willen participeeren. Ten welken eynde men by afzonderlyke, en by compagnieschappelyke onderneemingen, zodanige zuyker Plantagien zoude kunnen formeeren en etablisseeren, waartoe in vier jaaren noodig zou weezen 't Fournissement van cca $f 90.000$ a $f 100.000$. In den beginne zoude men dienen zooveel moogelyk eenige oude 't werk gewoone slaaven aan te koopen of te huren by de nieuw aan te brengene of aan te koopene.

De Particuliere of de Compagnieschappen zouden kunnen scheepen uytrusten om de noodige slaaven van de kust van Guinea te haalen en derwaarts aan te brengen, dog niet eer voor dat' er slaave kost geplant is, dat wel zou kumen gesteld worden. $1^{1 / 2} / 2$ jar na de eerste Boschvelling begonnen zou zyn. Insgelyks zou een scheepje kunnen gezonden worden om muyl Eesels van de kust van Barbaryen of elders daar se goed vallen te gaan haalen en derwaarts transporteeren. Zyude ondervonden dat de muyl Eesels sig vry beeter houden als Paarden.

Van zodanige Plantagie, die in den beginne niet anders dan met een Beeste werk kan, immers dient gemalkt te worden, zou men "t 5de of 6de jaar 200 en vervolgens 250 oxhoofden Zuyker kunnen maaken, mits de magt geduurende die jaaren jaarlyks boven de afgestorvene 8 a 10 slaaven worden vermeerdert, "t welk bereekend word als volgt:

Staande vooraf te noteeren, dat de plaats daar het na te meldene cordon zou sluyten een water gety, dat is ruym 8 uuren opvaarens van de mond legt, en dus de Landeryen aldaar onder de middellanden te sorteeren zyn, tot omtrend 2 a 3 uur hooger, als wanneer men het 
voor hoog Land kan reekenen alwaar 't noodige Bouwhout gevonden word. Voor een stuk Land groot 1000 akkers zoude tot het maaken van 't cordon gefourneerd of betaald worden:

Voor 't maaken van de Beeste moolen, het kookhuys en keetelwerk en wat daar toe behoord, Slaave Huuzen tot het bewerken, uytsleepe, transporteeren van hout en matterialen daar onder begreepen . . . . . . . . . . . . . - 12.000.-

N.B. behoeft zoo zwaar niet te weesen als hier ordinair gemaakt is vooral 't kookhuys

Woonhuys en verdere gebouwen alles op blokken . . . - 3.500. 75 slaaven: 40 mans en 35 wyven a $f 450$. . . . . . . -33.750 . 30 muyl Eesels a f 400 . . . . . . . . . . . . . . -12.000 gereedschappen, vaartuigen en extra kosten. . . . . . - 3.750.-

Hier komt by geduurende 3 jaaren dat'er niets gemaakt word, de kosten zoo van slaave kost, Directeurs, en andere Bedienden haar loon en kost, Landslasten $f 4000$ 's jaars is - 12.000 . -

Ter supleering der slaaven en die sterven de eerste drie jaaren 10 stuks 's jaars . . . . . . . . . . . . . . . -13.500.

$t$ 98.500.-

welke somma grootendeels 't eerste en tweede jaar zoude dienen gefourneerd te worden, na maate daarvan emplooy gemaakt word.

Zoo de zaake wel beleyt en voortgeset worden, zou men kunnen stellen dat het 3 de jaar nadat begonnen is, 50 a 60 oxhoofden zuyker kan worden gemaakt, 't 4de jaar 100, 't 5de jaar 150, 't 6de jaar 200 a 250 oxhoofden die thans buyten de malassie en dram $f 100$ à 120 't oxhoofd rendeeren vry geld, dog die men egter met de malassie en Dram, maar op $f 100$ Holl. 't oxhoofd moet stellen.

De 50 oxhoofden Revenuen van 't 3de jaar en de 100 van 't 4de jaar kunnen voor de Interessen en extra kosten die gesteld worden, als meede voor aankoop van de noodige slaaven zoo voor de afgestorvene als voor die noodig zullen zyn tot de vermeerderd wordende Cultuure gesteld worden, waarna de ordinaire sterfte, buyten extra ongelukken kan gesteld worden op 5 a 6 P.C. en dus de kosten op 6 à 7000 's jaars.

Dus het 5 de jaar 150 oxhoofden. . . . . . . . . $t$ 15.000.af voor onkosten, etc. hiervoor gemeld. . . . . . - 7.000.-

$$
\begin{aligned}
& \text { rest } \quad f 8.000 \\
& \text { 't } 6 \text { de jaar } 200 \text { oxhoofden ........... . } t 20.000 \text { - } \\
& \text { af idem . . . . . . . . . . } \frac{-7.000-13.000}{\text { rest }}
\end{aligned}
$$

Men zou wel moge onderstellen, dat met op gem. ${ }^{e}$ fournissementen wel (namaate 't land rendeerd) 250 ja zelfs 300 oxhoofden Zuyker zoude kunnen gemaakt worde, dog om zeeker te gaan zal best weese het by de bovenstaande calculatie te laate. En dan nog, gesteld dat de Zuyker weeder op $f 60$ a $f 65$ 't oxhoofd dat is met de malassie en Dram op $f 80$ a 85 daalde, zou 't nog circa $f 10.000$ vry geld opleeveren, dat 
eevenswel nog 12 a 13 p.c. intrest jaarlyks zou opbrengen, zoodat, al gesteld dat' er nog meerder daaling of eenig swaarder verlies van slaaven voorviel, zou men egter nog wel op tenminste 8 p.c. kunnen reekenen.

En zoo de Landeryen (gelyk verseekert word) boven 3 oxhoofden per Akker door malkander rendeeren, zou dikwyls met deselve magt 250 en zelfs tot 300 oxhoofden zuyker kunnen gemaakt worden. Om dit te animeeren zou de stadt Amsterdam mogelyk 10 a 12 zulke Plantagien kunnen aanleggen of, dat wel zoo voordeelig is, 6 dubbelde egter op differente plaatsen omdat de Landeryen zeer differeerende vallen.

Deeze Beestewerken kunnen zoo aangelegt worden, dat die in egaal land, dat is daar geen hinderlyke heuvelen of Bergen op zyn, door de tyd ligtelyk tot waterwerken kunnen verandert worden met de Trensen tot aan de moolen ter transporteeringe van 't Riet zoo te maaken, dat die door vergrooting ligtelyk tot een waterwerk kunnen dienen.

Voorts zouden meer zulke Compagnieschappen kunnen gemaakt worden, 't zy grooter of klijnder, tot de concurentie van 80 à 100 Plantagien enkelde of dubbelde na advenant. De rest boven zoo verre al te Bergagtig zal voor Houtgronden kunnen dienen, om die boven 't Cordon leggen derwaarts te verplaatsen enz. Dog om daar zeeker te kunnen werken, weesen en blyven zal het cordon volgens 't overgesondene Project dienen vervolgt en alles ingeslooten te worden, waardoor ook al de Rest vande colonie zoo verre die nu buyten 't cordon is, in zeekerheid zou gebragt zyn, waartoe de kosten op 1 Millioen gereekent worden tot het maaken, 20 à 30 . Duysend gulden tot jaarlyks onderhoud, en 1000 Man meerder ter besetting, waartoe in alles circa 220 a 230 Duysend guldens 's jaars zoude noodig zyn; Dog hierdoor zoude deeze zoo kostelyke Colonie met die voordeelige vermeerdering op alle wyze zeeker en bevyligt kunnen geacht worden, zelfs teegen alle vyanden. 